\title{
Methodology of Teaching Graphic Methods for Solving Problems with Parameters as a Means to Achieve High Mathematics Learning Outcomes at School
}

\author{
Venera G. Zakirova ${ }^{1}$, Natalia A. Zelenina ${ }^{2}$, Ludmila M. Smirnova ${ }^{3}$, Olga A. Kalugina ${ }^{4}$ \\ ${ }^{1}$ Kazan (Volga region) Federal University, Kazan, RUSSIA \\ ${ }^{2}$ Vyatka State University, Kirov, RUSSIA \\ ${ }^{3}$ I.M. Sechenov First Moscow Medical University (Sechenov University), Moscow, RUSSIA \\ ${ }^{4}$ Financial University under the Government of the Russian Federation, Moscow, RUSSIA
}

Received 8 December 2018 - Revised 3 February 2019 • Accepted 12 March 2019

\begin{abstract}
The introduction of new standards of mathematical education requires to stop understanding of the learning process as the transfer of ready-made knowledge and experience. Educational activity built on the principle of self-construction of knowledge by schoolchildren is highly demanded in new environment. Tasks with parameters have high learning, development, research and diagnostic potential. It allows to identify and in the process of teaching mathematics to prepare students who possess subject knowledge at the highest level, corresponding to the trends of the time. The urgency of the problem under study is determined by the need for students to form the ability to solve problems with parameters in order to achieve high results in mathematical, intellectual and personal development. The aim of the research is to develop a methodology for teaching students how to solve problems with parameters as an effective means of high-quality mathematical studies. The authors have identified main methods for solving problems with parameters and approaches to their study, and proved the theoretical basis for the application of these methods in the learning process. Therefore, they have shown the role of the propaedeutic stage of teaching graphic methods for solving problems with parameters, its goals, objectives and content. The authors suggest a methodology for designing a system of tasks that contributes to achieving high learning outcomes, which has passed multi-stage approbation. Moreover, they prove the need to use the Live Mathematics software as an effective visualization tool for studying graphic methods for solving problems with parameters. The methodology described in the article can be used by teachers at school and extracurricular mathematics classes, by the authors of textbooks for students and teachers, and it can also be the basis for a special course for students of pedagogical universities.
\end{abstract}

Keywords: teaching mathematics, problems with parameters, methods for solving problems with parameters, system of problems, teaching methods

\section{INTRODUCTION}

\section{The Relevance of the Research}

The most important requirement for schools graduates now is the formation of an active position in acquiring deep and solid knowledge, the ability to intelligently and creatively apply them (The concept of development of mathematics education in the Russian Federation, 2013). The implementation of this requirement is ensured by an

(C) 2019 by the authors; licensee Modestum Ltd., UK. This article is an open access article distributed under the terms and conditions of the Creative Commons Attribution License (http://creativecommons.org/licenses/by/4.0/).

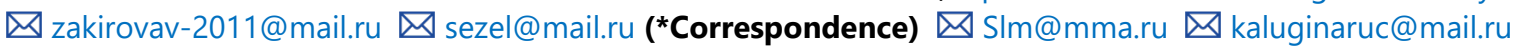




\section{Contribution of this paper to the literature}

- The authors suggest a methodology for teaching graphic methods for solving problems with parameters, based on specially designed task systems. The introduction of the developed methodology allows to realize the significant didactic potential of the considered tasks, which contributes to the achievement of high learning outcomes.

- The article substantiates goals and objectives of the propaedeutic stage of teaching pupils' graphic methods for solving problems with parameters, shows its content and methods of implementation using the Live Mathematics software complex.

- The authors offer didactic materials with methodological instructions and comments for teaching graphic methods for solving problems with parameters at school.

education system focused on the development and maintenance of high motivation and interest in the subject, heuristic and research skills, and creative abilities of schoolchildren (Galiullina, 2018; Popova, Gumerov \& Popova, 2017). Therefore, it is relevant to search and methodically process the content of learning mathematics, which satisfy the above requirements. Tasks with parameters have high learning, developmental, research and diagnostic potential. Solving problems with parameters combines assimilation, repetition, systematization and generalization of the studied material, as well as discovery of new knowledge by students. The ability to solve such problems indicates a high mathematical preparation of students. Using tasks with parameters, we can check knowledge of the main sections of the school curriculum, the level of logical thinking, research skills, the ability to substantiate one's actions, to prove findings. Tasks with parameters have always had a special place in school mathematics and played an important role in competitive selection procedures, which is quite justified (Zelenina \& Krutikhina, 2018). Methodical literature considers certain aspects of teaching pupils to solve such problems and, as a rule, they are devoted to the consideration of solutions to individual problems or groups of problems (Osipchukova, Klepikov \& Ziyatdinova, 2017). Famous mathematicians, teachers, methodologists point out the significant potential of this meaningful line for teaching, developing and educating schoolchildren, as well as for improving the process of teaching mathematics. At the same time, practice shows that most schoolchildren and some teachers are scared to solve problems with parameters. Possibilities of these tasks are not used enough in the practice of teaching at school. The causes of this phenomenon are psychological and / or substantive unwillingness of teachers to include such tasks in the lesson material; the lack of the system of these tasks in school textbooks and manuals for extra-class work, the lack of methodological recommendations on the organization of training, which indicates the absence of a methodology for working with such tasks. Thus, there is a contradiction between the significant potential of these problems to achieve high learning outcomes and the lack of development of the theory and methodology for its use in the education process. The goal of our research is to show that the use of teaching methods for teaching graphic methods of solving problems with parameters in the process of teaching mathematics contributes to the formation of deep, strong, conscious knowledge of schoolchildren, which can significantly improve the quality of teaching.

\section{Goals and Objectives of the Study}

The purpose of the research is to develop the theoretical and methodological foundations of teaching graphic methods for solving problems with parameters as a means of achieving high results in teaching mathematics at school. The main tasks are: analysis of the role and place of problems with parameters in the mathematical preparation of students; studying the mathematical content of learning to solve problems with parameters; consideration of functional graphic and geometric methods as the basis of visualization when solving problems with parameters; analysis of the capabilities of the Live Mathematics software package for the implementation of graphic solution methods; designing a system of tasks with parameters for individual topics; compiling didactic materials for teaching problem solving with parameters using graphic methods.

\section{LITERATURE REVIEW}

The ideas and experience of using problems with parameters as a means of forming students' high mathematical culture, intellectual and personal development in the process of teaching mathematics are discussed by many scientists, mathematicians, and specialists in the field of teaching mathematics. Most of the works are collections of problems with parameters, where a large number of examples of their solution are considered and the basic techniques and methods are highlighted. An extensive class of such problems is presented by Yastrebinetsky (1986), Gornshtein, Polonsky and Yakir (1992), Shestakov and Yurchenko (1993), Amelkin and Rabtsevich (2004), Gorbachev (1998), Natyaganov and Luzhina (2003), Vavilov et al. (2007), Golubev (2007), Lee, Lee, and Park (2016), Cho and Tee (2018), Pinho and Carvalho (2016), Muthelo and Chigonga (2018), etc. The authors have presented a wide variety of equations, inequalities and their systems containing a parameter. However, it is rather difficult for 
a teacher and a student to work with such literature if their goal is to begin studying approaches to solving such problems. Bashmakov (1976), Vazhenin (1997), Dalinger (1999), Dorofeev (1983), Litvinenko and Mordkovich (1983) have studied the role of problems with parameters in teaching mathematics, the concepts associated with their solution. Most of the authors characterize these tasks as research, requiring high logical culture, contributing to the assimilation of the scientific foundations of mathematics, the formation of creative personality qualities. This underlines the importance of such tasks for the formation of an active, thinking student. Golubev (1991), Olekhnik, Potapov and Nesterenko (1992), Dorofeev, Potapov and Rozov (1999), Modenov (2002), Sergeev (2005), Kozko and Chirsky (2007), Kozhuhov (2010), Swetz and Chi (1983) underline the importance of teaching pupils how to solve problems with parameters in connection with the need to prepare students for final tests and various competitions. Prestigious universities always include these tasks in the exam as diagnostic. Unified State Exam in Mathematics in all modifications of the last decade is no exception. Tasks with parameters, methods for solving them are a special section in the manuals for universities applicants and in literature for preparation for the state final exam. Markov (1970), Modenov (2007), Koryanov and Prokofiev (2011), Karasev and Levshina (2013), Zdorovenko, Zelenina and Krutikhina (2016), Zdorovenko and Zelenina (2018) consider graphical methods for solving problems with parameters as a means of visualizing the process of learning to solve them. They provide meaningful examples of solving equations, inequalities and their systems with parameters based on their graphic and geometric images. Tokareva and Zelenina (2016), Arcavi (2003), Bhagat and Chang (2015) consider the possibilities of using information and communication technologies to visualize the process of finding solutions to complex problems of elementary mathematics. Various aspects of teaching students how to solve problems with parameters are the subject of PhD research. Let us distinguish their main directions. Tolpekina (2002) considers the tasks with parameters as the basis for the organization of students' educational research. Shivrinskaya (2002) substantiates the possibility of using problems with parameters as a means of increasing motivation in teaching mathematics. The method of forming generalized methods for solving equations and inequalities with parameters for students in 89 grades is presented in Aryutkina's PhD (2002). The study by Miroshin (2008) reflects the formation of the contentmethodical line of problems with parameters in the course of secondary school mathematics on the example of linear, fractional rational and quadratic functions. In addition, consideration of tasks with parameters in educational activities allows to consider various methods and approaches to their solution, vary the problem situation, find new problems and ways to research them. It allows to establish numerous diverse links between mathematical concepts and facts, to generalize, systematize the knowledge of schoolchildren, which contributes to high-quality mathematical training. The importance of this component in teaching mathematics is highlighted by Poya (1991), Ivanova (1992), Evnin (2000), Baranova (2003), Gotman and Skopets (2000), Kozhukhov and Kozhukhova (2010a, 2010b), Wilkie (2016), Schukajlow, Achmetli and Rakoczy (2019). Without diminishing the value of the analyzed studies, it should be noted that their authors consider certain aspects of the inclusion of problems with parameters in the process of teaching mathematics to schoolchildren, relating either to the content of the tasks, or considering individual classes of problems, or descriptions of the meaning for the intellectual development of schoolchildren. The consequence of this is the lack of a unified approach to the design of a system of tasks and its application in the learning process, which would allow organizing the study of this material in the most effective way.

\section{MATERIALS AND METHODS}

\section{Theoretical Basis of the Study}

The theoretical and mathematical basis for teaching pupils to solve problems with parameters is the typology of methods for solving such problems presented in scientific and educational literature. There are four groups of methods: algebraic, functional, functional-graphic and geometric. Algebraic methods for solving equations, inequalities with a parameter and their systems include: reducing the problem to an equivalent, logical enumeration, replacing a variable, identifying necessary and sufficient conditions or necessary conditions. Functional methods for solving problems with parameters are: using the continuity of a function (interval method, rationalization method), using the function boundedness (estimation method, non-negativity of the function, largest and smallest values), using monotonicity (on the set of real numbers, on the interval, functions of different monotonicity), and using the derivative function. Many tasks for the study of an equation or inequality with the parameter $a$ can be written as $f(x ; a) \vee g(x ; a)$, where $\vee$ replaces one of the signs $=,>,<, \geq, \leq$. Depending on the role of the parameter in the task (the parameter is a fixed number or the parameter is a variable), the entry $f(x ; a)$ is considered either as a family of functions with variable $x$, or as an expression with two variables $x$ and $a$. In accordance with this, two main functional-graphical methods for solving problems with parameters are used - the construction of a graphical image of the problem on the $O x y$ coordinate plane (in the "variable-variable" system) or on the Oxa (in the "variable-parameter" system). The geometric method is based on the use of a geometric interpretation of equations or inequalities, an analytical definition of a line, a segment, a circle, a rhombus, a 
parallelogram, and other geometric objects. The theoretical and methodological basis of the research is the theory of teaching the subject through problems developed in the method of teaching mathematics (Kolyagin, 1977; Krupich, 1995; Sarantsev, 1995, 2002). According to this theory, it is necessary to apply specially designed task systems in the learning process in order to achieve goals. The greatest effect can be achieved if the work with such tasks allows: 1) to generalize and systematize the students' knowledge, 2) to demonstrate intra-subject relations between the concepts and facts used in the process of solving problems; 3) to transfer existing knowledge to a new problem situation, which is a sign of the inclusion of students in creative activities, 4) to include students in the research process.

\section{Research Methods}

The following methods were used to conduct the study: interviews, questioning students and teachers, analyzing scientific and methodological literature on the research topic, analyzing and summarizing the experience of teachers and their own work experience in the system of secondary and higher mathematical education, analyzing learning activities and its results, systematizing and generalization of facts and concepts, development of didactic materials, diagnostic tools, pedagogical experiment.

\section{Testing, Compilation and Implementation of Research Results}

Testing, compilation and implementation of the results of the study were carried out in the process of working with pupils of 8-11 grades of schools and lyceums of Kazan, Kirov and Moscow cities, as well as with students of 1-4 courses of Kazan (Volga region) Federal University, Vyatka State University, Sechenov University and Financial University under the Government of the Russian Federation:

- at the classes of the elective course "Tasks with Parameters" in 10-11 grades of Kazan, Kirov and Moscow lyceums (2013-2018); Lyceum of Natural Sciences and Lyceum number 21 of the city of Kirov (2016-2018). (72 hours in each class, more than 100 students annually);

- at the classes "We build graphs of equations" with students of 8-9 grades of Kazan, Kirov and Moscow cities during the summer intellectual shift in the school camp (2013-2018). (20 hours, 30-40 students annually);

- while studying the disciplines "Equations and inequalities", "Visualization methods in teaching mathematics", "Extracurricular work in mathematics" in Kazan (Volga region) Federal University and Vyatka State University (2013-2018). (30-40 students annually).

The research had three stages.

At the first stage, we analyzed the state of the problem in the theory and practice of teaching schoolchildren. For this purpose, we carried out the study and analysis of psychological, pedagogical, mathematical and methodological literature on the problem of research, observation and analysis of the experience of teachers of mathematics on the subject of teaching graphic methods for solving problems at school.

At the second stage, methodological recommendations were developed and didactic materials were developed for teaching students how to solve problems with parameters using graphical methods as part of special courses, summer intellectual shift. Discussion of the implementation of the methodological recommendations was carried out and continues to be carried out through feedback from teachers of mathematics, as well as during presentations at conferences and seminars at various levels, which leads to a consistent improvement of the proposed methodology.

In parallel with the second, the third stage was carried out and continues to be implemented, during which the authors and teachers of mathematics schools in Kazan, Kirov and Moscow cities, conduct experimental teaching and testing of the proposed recommendations.

\section{RESULTS}

\section{Typology of Problems with Parameters Solved by Graphical Methods}

The basis of graphic and geometric methods for solving problems with parameters is the ability to build graphs of elementary functions, graphic images of various equations, inequalities and their systems, including those dependent on the parameter. It is also important to be able to interpret the results obtained in accordance with the condition of the problem. Therefore, students must have certain knowledge and insights. It is important to show students the distinctive features of the tasks that can be solved by one of the graphical methods or by invoking geometric reasoning. The study and analysis of graphical and geometric methods for solving problems with parameters are three groups of problems that can be solved by the indicated methods (Table 1). The study allowed to identify basic knowledge and skills for each type, the implementation of which occurs in the process of solving. 
Table 1. Typology of problems with parameters solved by graphical methods

\begin{tabular}{|c|c|}
\hline 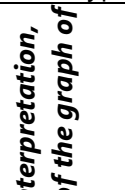 & $\begin{array}{l}\text { Tasks of the form } \boldsymbol{f}(\boldsymbol{x}) \vee \boldsymbol{a} \text { : in solving such problems on the coordinate plane } O x y \text { the function } y=f(x) \text { is } \\
\text { plotted. Then, for a given parameter } a \text { the set of solutions of the equation } f(x)=a \text { is the projection on the } \\
\text { abscissa of the intersection points of the horizontal line } y=a \text { with the graph of the function } f(x) \text {, and the } \\
\text { solution set of the inequality } f(x) \vee a \text { is the projection on the abscissa all points of the line } y=a \text {, if ordinates } \\
\text { satisfy the inequality } f(x) \vee a \text {. }\end{array}$ \\
\hline 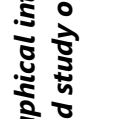 & $\begin{array}{l}\text { Tasks of the form } \boldsymbol{f}(\boldsymbol{x}) \vee \boldsymbol{g}(\boldsymbol{x})+\boldsymbol{a} \text { : when solving problems of this type, the family of functions } g_{a}(x)=g(x)+a \\
\text { is used, which graphs differ from the graph of the function } y=g(x) \text { by shifting along the Oy axis by a units up } \\
\text { at } a>0 \text {, and down at } a<0 \text {. }\end{array}$ \\
\hline 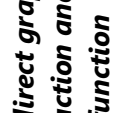 & $\begin{array}{l}\text { Tasks of the form } \boldsymbol{f}(\boldsymbol{x}) \vee \boldsymbol{g}(\boldsymbol{x}+\boldsymbol{a}) \text { : when solving problems of this type, the family of functions } g_{a}(x)=g(x+a) \\
\text { is used, the graphs of which differ from the graph of the function } y=g(x) \text { by shifting along the axis } O x \text { by } a \\
\text { units to the left at } a>0 \text {, and to the right at } a<0 \text {. }\end{array}$ \\
\hline 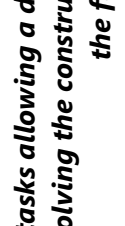 & $\begin{array}{l}\text { Tasks of the form } \boldsymbol{f}(\boldsymbol{x}) \vee \boldsymbol{a}\left(\boldsymbol{x}-\boldsymbol{x}_{\mathbf{0}}\right)+\boldsymbol{y}_{\mathbf{0}} \text { : the family of functions of the form } f_{a}(x)=a\left(x-x_{0}\right)+y_{0} \text { corresponds } \\
\text { to the family of lines passing through the point }\left(x_{0} ; y_{0}\right) \text {. The parametera plays the role of the angular } \\
\text { coefficient of the indicated straight lines. When changing the parameter values, we get straight lines that differ } \\
\text { from each other by the angle of inclination to the positive direction of the axis } O x \text {, that is, obtained by turning } \\
\text { around the point }\left(x_{0} ; y_{0}\right) \text { - the center of rotation. In this case, the set of lines passing through the point } \\
\left(x_{0} ; y_{0}\right) \text {, is also called the pencil of lines, and the point }\left(x_{0} ; y_{0}\right) \text { is the center of the pencil, respectively. }\end{array}$ \\
\hline 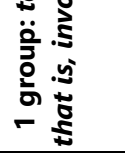 & $\begin{array}{l}\text { Tasks of the form } \boldsymbol{f}(\boldsymbol{x}) \operatorname{Vag}(\boldsymbol{x}) \text { : when solving problems of this type, the family of functions } g_{a}(x)=a g(x) \text { is } \\
\text { used, which graphs differ from the graph of the function } y=g(x) \text { by compression (stretching) along the axis } \\
O y \text { : by stretching if } a>1 \text {; by compression at } 0<a<1 ; \text { symmetry transformation about the axis } O x \text {, if } a=-1 \text {; } \\
\text { a combination of these transformations for the remaining values } a \neq 0 \text {. }\end{array}$ \\
\hline 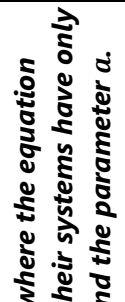 & $\begin{array}{l}\text { Tasks of the form } \boldsymbol{a} \vee \boldsymbol{\varphi ( x )} \text { или } \boldsymbol{x} \vee \boldsymbol{\psi}( \\
\text { possible to express one variable in term } \\
\text { parameter to a task without a paramete } \\
\text { other. In this case, the original equation } \\
\text { case, the graph of the function } \varphi(x) \text { (ine } \\
\text { graph of the function } \psi(a) \text { (the graphica } \\
\text { resulting graph (region) in straight lines } \\
\text { straight lines are given by the equation }\end{array}$ \\
\hline 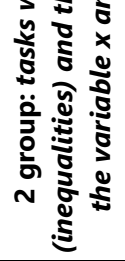 & $\begin{array}{l}\text { Tasks of the form } \boldsymbol{f}(\boldsymbol{x} ; \boldsymbol{a}) \vee \mathbf{0} \text { : to solve inequalities of this type, as a rule, the "area method" is used: find the } \\
\text { region of permissible values of a variable and a parameter on the coordinate-parametric plane; to build on the } \\
\text { coordinate-parametric plane lines, consisting of all points, with the values of the coordinate } x \text { and the } \\
\text { parameter } a \text { where each expression } f(x ; a) \text { vanishes or does not exist, and divide by these lines the resulting } \\
\text { range of valid values into "partial regions"; examine the sign of the expression } f(x ; a) \text { in each of the obtained } \\
\text { "partial areas" (for this, it suffices, for example, to set the sign of the expression } f(x ; a) \text { at some point of each } \\
\text { "partial area") }\end{array}$ \\
\hline 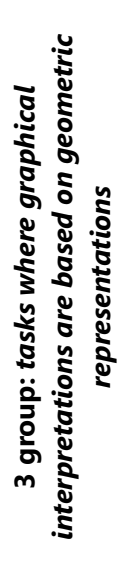 & 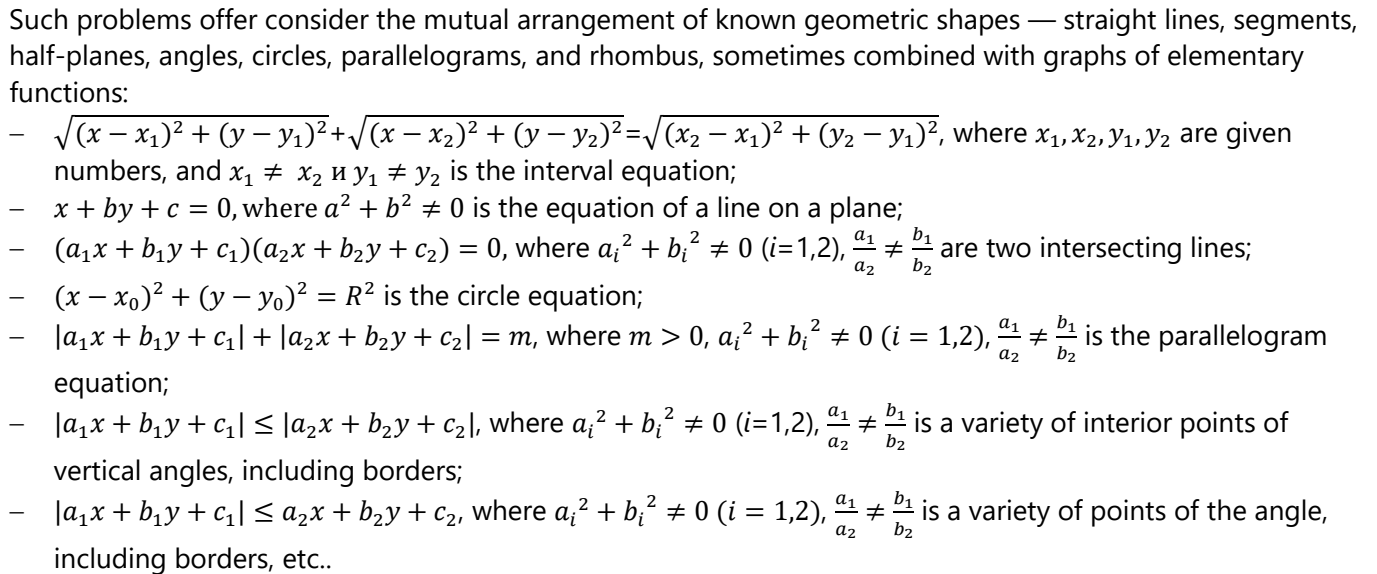 \\
\hline
\end{tabular}

\section{The Main Objectives of the Propaedeutic Stage in Teaching Pupils to Solve Problems with Parameters by the Graphical Method}

For the successful implementation of teaching graphic methods for solving problems with parameters, the propaedeutic stage of learning is important. The essence of this stage is to teach schoolchildren to construct the geometric places of the points given by equations, inequalities and their systems. This work can be purposefully carried out both during lessons, in extracurricular classes in mathematics, and in a special course (20 hours). As a 
result of the study, we have determined an optimal program of such a special course, developed didactic materials for its implementation, which contain recommendations on the use of the Live Mathematics software in the learning process. Classes are usually conducted in the form of laboratory work.

\section{Application of the Software Package "Live Mathematics" in Teaching Problem Solving with Parameters}

The analysis of capabilities of the Live Mathematics program for teaching graphic and geometric methods for solving problems with parameters makes it possible to note the following. The program is freely available, takes a little space (about $2 \mathrm{MB}$ ), you can take it everywhere, which allows to organize work in any audience equipped with a computer (laptop) and a projector. This underlines its demonstration capabilities and application as an effective means of visualization. The program can also be easily used by students in the process of solving problems, being a means of learning, maintaining interest in the subject. The program performs a wide range of operations related to the construction of graphs of functions and geometric objects, which are graphic images of the corresponding equations, inequalities and their systems, as well as their transformations. "Live Mathematics" allows to dynamic modification the graphs of functions that depend on the parameter. Therefore, it can be considered as an effective means of visualization when teaching graphic methods for solving problems with parameters.

In the course of the study, we developed didactic materials to organize the training graphic methods for solving problems with parameters. These materials include an extensive bank of tasks, systematized in accordance with the pupils' knowledge of functions, graphs, graph transformations, geometric locations of points given by equations, inequalities and their systems. The methodological recommendations for the teacher include solutions to the problems, as well as electronic drawings for the tasks performed in the Live Mathematics, including animations.

\section{The Main Stages of Solving the Problem with the Parameter Using Graphic Methods}

The solution of the problem with the parameter by the graphic method has several stages. Let us characterize them. At the first stage, the equation (inequality or their system) is converted to a form that allows to get its graphic image. Here, as a rule, we use identical transformations, equivalent transitions for solving basic types of equations and inequalities, factoring any part of the equation or inequality, etc. At the second stage, we construct the graphs of equations, inequalities or their systems. Here we apply knowledge of the properties and graphs of basic elementary functions, graph transformations, symmetries of graphs of functions, the ability to investigate a function by methods of differential calculus, etc. The third stage is a "reading of the drawing". Here it is important to teach students to correctly interpret the information obtained using the drawing, to correctly translate from a graphic (geometric) language to an analytical one. In this case, attention should be paid to the peculiarities of reading the drawing in cases of using various graphical methods for solving the problem. At the fourth stage, the information obtained using the drawing is justified, the found values of the parameters are confirmed analytically, the fact of the absence of other values that satisfy the condition of the problem is established. In the learning process, schoolchildren should be shown how to work with a task at each stage. From these positions, tasks that allow several solutions have the most didactic and methodical value. We should pay special attention to it when forming a bank of tasks. Each task is provided with methodological comments regarding the applied solution methods. Let us give an example of the implementation of two different graphical ways of solving a problem with a parameter from a compiled task bank with a demonstration of the capabilities of the "Mathematical Designer".

Task. Find all the values of the parameter a, for each of which the system of equations

$$
\left\{\begin{array}{c}
y^{2}+x y-4 x-9 y+20=0 \\
y=a x+1, \\
x>2
\end{array}\right. \text { has the only solution. }
$$

Let's transform the first equation of the source system:

$$
\begin{gathered}
y^{2}+x y-4 x-5 y-4 y+20=0 ; y(y-4)+x(y-4)-5(y-4)=0 ; \\
(y-4)(y+x-5)=0 .
\end{gathered}
$$

Schoolchildren should be noted here that there are other methods of factoring a polynomial in two variables.

We can consider it as a square trinomial in the variable $y-y^{2}+(x-9) y-4 x+20$, find the roots $-y=4$ or $y=-x+5$ and apply the theorem on the expansion of the square trinomial into factors.

We can apply another grouping -

$$
y^{2}+x y-4 x-9 y+20=\left(y^{2}-9 y+20\right)+x y-4 x .
$$

Then, after factoring the square trinomial, we get $(y-4)(y-5)+x(y-4)=(y-4)(y-5+x)$.

So, as a result of factoring the left side of the first equation, the original system takes the form: 


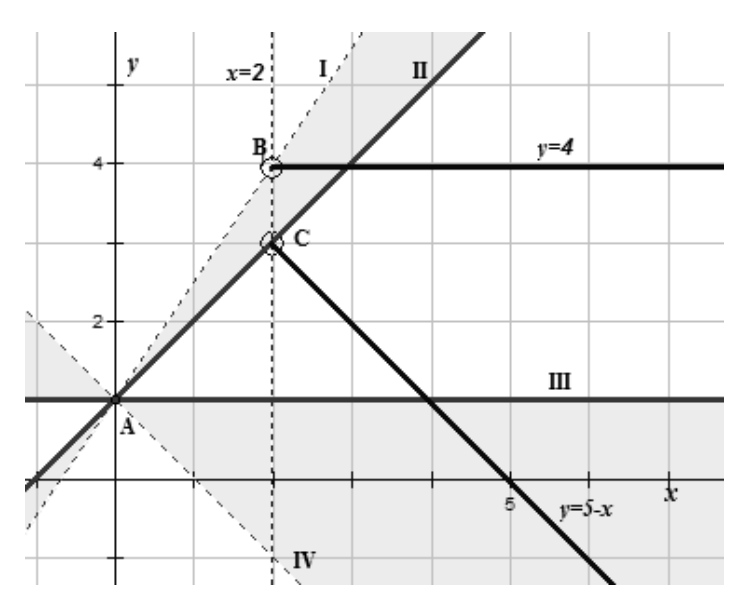

Figure 1. Drawing to the solution of the problem in the coordinate system $(x, y)$

$$
\left\{\begin{array}{c}
(y-4)(y+x-5)=0, \\
y=a x+1 \\
x>2
\end{array}\right.
$$

Let us solve the problem graphically in the coordinate system $(\boldsymbol{x}, \boldsymbol{y})$.

From the system (1) we get $\left\{\begin{array}{c}y-4=0 \text { or } y+x-5=0, \\ y=a x+1, \\ x>2\end{array}\right.$, then

$$
\left\{\begin{array}{c}
y=4 \text { or } y=5-x \\
y=a x+1 \\
x>2
\end{array}\right.
$$

In the coordinate system $(x, y)$ we will consider those parts of the straight lines $y=4$ and $y=5-x$, that lie in the half-plane $x>2$ (Figure 1).

The equation $y=a x+1$ sets a straight line on the plane passing through the point $A(0 ; 1)$ with an angular coefficient equal to $a$, which takes all possible values. It is convenient to imagine not a family of lines, but a "moving" line that "rotates" around point $A(0 ; 1)$. Rotating the straight line in mind $y=a x+1$, we define such positions when it has exactly one common point with parts of straight lines $y=4$ и $y=5-x$. Figure 1 shows areas in which the line $y=a x+1$ must be in order to meet this condition. Now let's find the values of $a$, which correspond to the positions of the straight, bounding data area.

I. The straight line $y=a x+1$ passes through the point $B(2 ; 4)$, therefore, $4=a \cdot 2+1$, hence $a=\frac{3}{2}$.

II. The straight liney $=a x+1$ passes through the point $C(2 ; 3)$, therefore,

$3=a \cdot 2+1$, hence $a=1$.

III. The straight line $=a x+1$ is parallel to the axis $O X$, therefore, $a=0$.

IV. The straight liney $=a x+1$ is parallel to the straight line $y=5-x$, therefore $a=-1$.

Thus, the condition of the problem is satisfied by $a \in(-1 ; 0] \cup\left[1 ; \frac{3}{2}\right)$.

To use such a method, it is necessary to teach schoolchildren to depict various sets of points on a plane, which can be done by studying specific classes of functions.

Let's solve the problem graphically in the coordinate system $(\boldsymbol{x}, \boldsymbol{a})$.

Let's substitute $y=a x+1$ in the first equation of system (1), we get

$$
\left\{\begin{array}{c}
(a x-3)(a x+x-4)=0, \\
x>2 .
\end{array}\right.
$$

Note that each value of $x$ corresponds to exactly one value $y=a x+1$ for each fixed value of the parameter $a$, that is, the original system has as many solutions as system (3). Let's find all values for which system (3) has a unique solution.

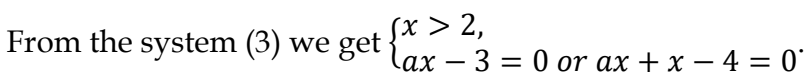

As $x>2$, then $x \neq 0$ and

$$
\left\{\begin{array}{l}
x>2, \\
a=\frac{3}{x} \text { or } a=\frac{4}{x}-1
\end{array}\right.
$$




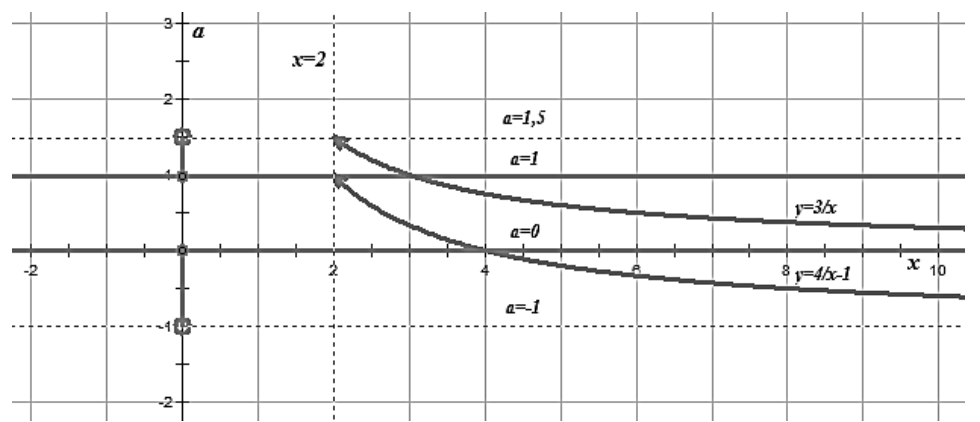

Figure 2. Drawing to the solution of the problem in the coordinate system $(x ; a)$

Table 2. The results of the survey of teachers of mathematics

\begin{tabular}{lcc}
\hline & Do you solve problems with parameters in maths lesson? \\
\cline { 2 - 3 } Answer & Yes, regularly & $0 \%$ \\
\cline { 2 - 3 } options: & Yes, occasionally & $10.2 \%$ \\
\cline { 2 - 3 } & No, I do not have sufficient mathematical and / or methodological training on this issue & $51.7 \%$ \\
\hline
\end{tabular}

Let's construct in the coordinate $\operatorname{system}(x, a)$ the set of all points which coordinates satisfy system (4). To do this, in the half-plane $x>2$ we construct the hyperbolas $a=\frac{3}{x}$ and $a=\frac{4}{x}-1$ (Figure 2).

Let's find the point of intersection of the hyperbole by solving the system $\left\{\begin{array}{l}a=\frac{3}{x} \\ a=\frac{4}{x}-1\end{array}\right.$, where $\frac{3}{x}=\frac{4-x}{x}$, that is $x=$ 1 , which does not satisfy the condition $x>2$. It means that in the half-plane $x>2$ hyperbolas do not intersect.

Let's note at $x=2$ the value of $a=\frac{3}{x}$ is $\frac{3}{2}$, the value of $a=\frac{4}{x}-1$ is 1 , that is at $x>2$ we have $\frac{3}{x}>\frac{4-x}{x}$.

Moving the straight line in mind $a=$ const along the axis $O a$ "from the bottom up", we fix its positions in which this straight line has exactly one common point with parts of hyperboles (in Figure 2, the corresponding values of the parameter $a$ are marked on the axis $O a$ ). Thus, the original system has a unique solution for $a \in(-1 ; 0] \cup\left[1 ; \frac{3}{2}\right)$.

Let us note that work in the variable-parameter system is unusual for students from the point of view of getting the answer. However, if the method is familiar and assimilated, we see that solving the problem is reduced to plotting known functions and solving familiar equations, inequalities and their systems.

\section{Results of the Experimental Part of the Study}

During the implementation of the experimental part of the survey, we surveyed 118 mathematics teachers from secondary schools. The survey results are shown in Table 2.

More than $60 \%$ of respondents offer tasks with parameters to their students either occasionally or not at all. One of the main reasons is the steady opinion of teachers that such tasks will be too difficult for students. Approximately one fifth of the teachers surveyed noted that they sometimes consider equations with parameters in extracurricular classes, most often in order to prepare for final exam. Almost $18 \%$ of teachers believe that in order to successfully work with such tasks in mathematics lessons they need special mathematical and methodical training. The method developed by us for teaching graphical methods for solving problems with parameters was presented at courses for mathematics teachers. We conducted a series of lectures and practical exercises. Expert evaluations of teachers who attended the courses were positive. They consider the developed didactic materials and guidelines for them to be the strength of the proposed methodology, they note the importance and simplicity of implementation in the process of learning the propaedeutic stage of teaching graphic methods for solving problems with parameters. In the opinion of teachers, the Live Mathematics program is a fairly simple and effective means of visualizing the process of solving such complex problems.

In the course of the study, we also surveyed students of 8-11 grades of secondary schools (about 100 people). The question was "How do you feel about tasks with parameters and would you like to learn how to solve such tasks?" The most common answers were: I have never tried to solve problems with parameters; they are very difficult; this material can be mastered only by students of specialized mathematical schools; I am afraid of such tasks. However, it should be noted that, despite the students' certain fear of these tasks, some of them still show interest in them and do not mind trying to learn how to solve problems with parameters. Note also that for a certain 
Table 3. Percentage of students who received certain points for solving a problem with a parameter on the Unified State Exam in Mathematics (profile level), \%

\begin{tabular}{cccccc}
\hline Number of points & $\mathbf{4}$ & $\mathbf{3}$ & $\mathbf{2}$ & $\mathbf{1}$ & $\mathbf{0}$ \\
\hline Experimental group & $10.3 \%$ & $4.4 \%$ & $10.3 \%$ & $23.5 \%$ & $51.5 \%$ \\
\hline
\end{tabular}

part of students this desire is purely pragmatic and is associated with preparation for the final exam. For more than 10 years, the task with the parameter has been included in the control and measurement materials of the Basic (for the course of the nine-year school) and the Unified (at the end of eleven classes) state exams.

Testing the effectiveness of the developed methodology for teaching graphic methods for solving problems with parameters was carried out in the special course "Tasks with parameters". Classes were held during the school year in the amount of 72 hours. Three year courses were conducted (2015 - 2018 academic years). Pupils of 11 classes (68 people) took part in the approbation. Within the course, the main methods for solving problems with parameters were considered. Separate classes were devoted to the consideration of graphic and geometric methods for solving this class of problems with the use of the Live Mathematics software complex (the classes were equipped with a projector, an interactive whiteboard, a computer). The program was used to explain the basic ideas and methods of solving, finding a plan for solving the problem, checking independently solved tasks, and checking homework. The use of dynamic drawings in the course of the work made it possible to make the explanation clear, understandable, and easily perceived. The implementation of the problem solving check with the use of the Live Mathematics program made it possible to significantly save time and, as a result, increase the density of classes, the number of solved problems and the theoretical issues considered. As indicators of the performance of classes, we present the results of solving a problem with a parameter (No. 18) for students of 11 classes who attended special course classes in 2016-2018 (experimental group) at the Unified State Examination in Mathematics (profile level). The task with the parameter has 4 points for a complete and reasonable decision, 3, 2, 1 points depending on the errors made in the decision. The following tasks were proposed for the exam in 2016-2018.

2016 : Find all values of $a$, for each of which the equation $\sqrt{x^{4}-x^{2}+a}=x^{2}+x-a$ has exactly three different roots.

2017 : Find all values of $a$, for each of which the equation $\sqrt{4 x-3} \cdot \ln (2 x-a)=\sqrt{4 x-3} \cdot \ln (3 x+a)$ has exactly one root on the segment $[0 ; 1]$.

2018 : Find all values of $a$, for each of which the set of equations $\left\{\begin{array}{c}x^{2}+y^{2}-4(a+1) x-2 a y+5 a^{2}+8 a+3=0 \\ y^{2}=x^{2}\end{array}\right.$ has four different solutions.

Let us note that all the examination tasks are allowed to have graphical solutions or solutions based on geometric representations (Table 3).

Note that about half of the exam participants received points for solving this problem in the experimental group, while each year, on average, they do not start solving this task or more than $90 \%$ of the examinees receive 0 points for solving it. Indicative is the statistics of the maximum score - the excess of more than 10 times. We also note that almost all participants in the special course "Tasks with Parameters" who received points for problem number 18 (about $50 \%$ ) scored from 76 to 90 points (out of 100 points) at the state final exam in mathematics. On average, about $6 \%$ of graduates in the region have such a result (Zelenina \& Krutikhina, 2018).

The results of the student survey at the end of the special course, showed that the attitude towards such tasks shifted from their rejection towards interest. It is evidenced by the following evaluative judgments of schoolchildren: problems are interesting; tasks are unusual, not the same as in school textbooks; I like to solve problems with parameters graphically; I'm not afraid to solve the problem with the parameter, if it can be solved graphically.

Thus, the experiment confirmed our assumption about the positive impact of the method of teaching graphic methods of solving problems with parameters on the quality of students' knowledge of mathematics, the ability to solve complex problems in the course of elementary mathematics. We also confirmed the assumption that in the course of traditional learning (without updating the ideas presented in the work of the method), the ability to solve problems with parameters is formed, but the level of development of this skill is much lower than in the case of regular use of the method of targeted training developed by us.

\section{DISCUSSIONS}

The study has shown that issues related to teaching pupils how to solve problems with parameters are widely discussed in the scientific and methodological literature. Many researchers see the great potential of such tasks for improving the quality of teaching mathematics to schoolchildren, since the student's activity in solving problems of this level and content is informal, deliberate, and exploratory in nature. Solving problems with parameters 
requires depth of reasoning, solid basic knowledge, a certain level of logical thinking, volitional qualities. Not all schoolchildren are ready to work with such tasks, due to their abilities and motivation. However, our experience of working with students in 8-11 grades shows that some of them perceive this material with interest, they are attracted by the novelty of tasks and reasoning, the unusual methods of solutions, and when certain success is achieved, interest in problems with parameters increases. It significantly affects the quality of students' preparation in mathematics, including various kinds of appraisals, allows to remove the psychological barrier to such tasks and by the end of 11 grade to acquire a certain experience in solving problems with parameters. The problem is to include the student in such activities systematically. It is important for the teacher to realize the significance of such tasks, their great opportunities for the development of the student, the achievement of high learning outcomes, and also to master the teaching methods. It requires theoretical teacher training and a workshop on the use of the proposed methodology. These questions can be a subject of discussion when preparing students for pedagogical areas of training (Mathematics profile) when studying the theory and methodology of teaching mathematics, elementary mathematics, and geometry. It is possible to organize coursework for advanced training of teachers of mathematics.

\section{CONCLUSION}

Based on the analysis of scientific, pedagogical and methodological literature, the study of the experience of teachers and their own teaching experience, a method of teaching schoolchildren to graphical methods for solving problems with parameters has been developed and introduced into practice. Years of experience with schoolchildren and students show that the most preferable in the first stages of training are graphical ways of reasoning when solving problems with parameters. They are less cumbersome and time consuming, more understandable and visual, which greatly facilitates the work with the task. However, it does not mean that in order to master the graphical and geometric methods of solving problems with parameters, the demands to knowledge and skills of students are different. Overcoming difficulties in teaching students to graphical methods for solving problems with parameters is promoted by the use of the developed method. Its main points are the following. The importance of the propaedeutic stage, the aim of which is the purposeful work on the formation of the ability to build graphic images of equations, inequalities and their systems, graphs of functional dependencies. This stage can be implemented at the lessons of mathematics in 8-9 grades. A specially designed system of tasks systematized in accordance with the pupils' knowledge of functions, their graphs, graph transformations, geometric locations of points given by equations, inequalities, and their systems. The basis of building a system of tasks is the typology of problems given in the study with parameters solved by graphic methods. Visualization of finding solutions to problems with parameters using graphical methods through the use of the Live Mathematics software system in classrooms shows the educational, developmental and educational potential of studying the subject.

\section{RECOMMENDATIONS}

The materials of the article can be useful for teachers of mathematics, teachers of additional mathematics education, teachers of higher educational institutions who are interested in significantly increasing the level of educational achievements of students, to maintain interest to the subject. Ways to improve the proposed methodology are in the improvement of sets of tasks on various topics of the course, the development of laboratory work for students of 8-9 grades using the Live Mathematics software package.

\section{ACKNOWLEDGEMENTS}

1. The work is performed according to the Russian Government Program of Competitive Growth of Kazan Federal University.

2. The publication has been supported by the 'Russian Academic Excellence Project 5 - 100' of the I M Sechenov First Moscow State Medical University (Sechenov University).

3. The work is performed according to the Program of Development of Federal State-Funded Educational Institution of Higher Education "Financial University under the Government of the Russian Federation" for 2020.

\section{REFERENCES}

Amelkin, V. V., \& Rabtsevich V. L. (2004). Tasks with parameters. Moscow: Asar.

Arcavi, A. (2003). The role of visual representations in the learning of mathematics. Educational Studies in Mathematics, 52(3), 215-241. https:/ / doi.org/10.1023/A:1024312321077

$10 / 12$ 
Aryutkina, S. V. (2002). Formation of generalized methods for solving equations and inequalities with parameters for students in 8-9 grades (PhD Thesis). Arzamas.

Baranova E. V. (2003). Special Course "Educational Studies in Teaching Mathematics". Mathematical Bulletin of Pedagogical Universities of the Volga-Vyatka Region. Issue 3: coll. of scientific method. works. Kirov: VSUH, pp. 246-247.

Bashmakov, M. I. (1976). Equations and inequalities. Moscow: Science.

Bhagat, K. K., \& Chang, C. Y. (2015). Incorporating GeoGebra into Geometry learning-A lesson from India. Eurasia Journal of Mathematics, Science \& Technology Education, 11(1), 77-86. https:/ / doi.org/10.12973/eurasia.2015.1307a

Cho, Y., \& Tee, F. (2018). Complementing Mathematics Teachers' Horizon Content Knowledge with an Elementaryon-Advanced Aspect. Pedagogical Research, 3(1), 03. https://doi.org/10.20897/ pr/85172

Dalinger, V. A. (1999). Formation of students' visual thinking in the process of learning mathematics. Omsk: OmGPU.

Dorofeev, G. V. (1983). On the compilation of cycles of interrelated problems. Mathematics at school, 6, 34-39.

Dorofeev, G. V., Potapov M. K., \& Rozov N. Kh. (1999). Mathematics. For those who enter universities. Moscow: Drofa.

Evnin, A. Yu. (2000). The study of the mathematical problem as a means of developing the creative abilities of students (PhD). Kirov.

Galiullina, E. R. (2018). Mastering the methods of generating ideas as a way to develop creativity. Vestnik NTSBGD, 1(35), 12-15.

Golubev, V. I. (1991). The absolute value of the number in competitive exams in mathematics. Lvov: Kvantor.

Golubev, V. I. (2007). Solving complex and nonstandard math problems. Moscow: Ileksa.

Gorbachev, V. I. (1998). Elements of the theory and general methods for solving equations and inequalities with parameters. Bryansk: BSPU.

Gornshtein, P. I., Polonsky, V. B., \& Yakir, M. S. (1992). Tasks with parameters. Kiev: Zhuravl.

Gotman, E. G., \& Skopets, Z. A. (2000). One problem but solutions are different. Moscow: Enlightenment.

Ivanova, T. A. (1992). Variation of mathematical problems as a means of developing the intellectual abilities of students. Student development in the process of teaching mathematics: Interuniversity collection of scientific papers. N. Novgorod: NGPI named after M. Gorky.

Karasev, V. A., \& Levshina, G. D. (2012). Solving problems with parameters using function graphs. Moscow: Ileksa.

Kolyagin, Yu. M. (1977). Tasks in teaching mathematics. Moscow: Education.

Koryanov, A. G., \& Prokofiev, A. A. (2011). Using the method of visual-graphic interpretation in solving equations and inequalities with parameters. Mathematics at school, 1, 25-32.

Kozhukhov, S. K., \& Kozhukhova, S. A. (2010a). Equations and inequalities with a parameter. Eagle: OIUU.

Kozhukhov, S. K., \& Kozhukhova, S. A. (2010b). On the methodological feasibility of solving problems in different ways Mathematics at school, 3, 42-44.

Kozko, A. I., \& Chirsky, V. G. (2007). Problems with a Parameter and Other Complex Problems. Moscow: MTSNMO.

Krupich, V. I. (1995). Theoretical Foundations of Teaching the Solution of School Mathematical Problems. Moscow: Prometheus.

Lee, K., Lee, E., \& Park, M. (2016). Task Modification and Knowledge Utilization by Korean Prospective Mathematics Teachers. Pedagogical Research, 1(2), 54. https:/ / doi.org/10.20897/lectito.201654

Litvinenko, V. N., \& Mordkovich, A. G. (1983). Workshop on solving problems of school mathematics. Moscow: Enlightenment.

Markov, V. K. (1970). The coordinate method and problems with parameters. Moscow: Enlightenment.

Miroshin, V. V. (2008). Formation of the content-methodical line of problems with parameters in the course of secondary school mathematics (PhD). Moscow.

Modenov, V. P. (2002). Mathematics for schoolchildren and applicants. Moscow: Institute of Computer Science.

Modenov, V. P. (2007). Tasks with parameters. Coordinate-parametric method: study guide. Moscow: Exam.

Muthelo, D., \& Chigonga, B. (2018). Attributes of Mathematics Enculturation: Sarah's Experiences in the Mathematics Classroom. Pedagogical Research, 3(1), 05. https://doi.org/10.20897/pr/87019

Natyaganov, V. L., \& Luzhina, L. M. (2003). Methods for solving problems with parameters. Moscow: Moscow University. 
Olekhnik, S. N., Potapov, M. K., \& Nesterenko, Yu. V. (1992). Competition problems in mathematics. Moscow: Science.

Osipchukova, E.V., Klepikov, A.V., \& Ziyatdinova, R.M. (2017). Additional professional education as a factor in increasing the competitiveness of students at Russian universities. Vestnik NTSBGD, 3(33), 47-52.

Pinho, E., \& Carvalho, A. (2016). Visualization System for Monitoring Data Management Systems. Journal of Information Systems Engineering \& Management, 1(4), 48. https:/ / doi.org/10.20897/lectito.201648

Popova N.V., Gumerov A.V., \& Popova E.V. (2017). Education of students in Russian universities: the motivational aspect. Vestnik NTSBGD, 2(32), 64-69.

Poya, D. (1991). How to solve a problem. Lvov: Kvantor.

Sarantsev, G. I. (1995). Exercises in teaching mathematics. Moscow: Enlightenment.

Sarantsev, G. I. (2002). Methods of teaching mathematics in high school. Moscow: Enlightenment.

Schukajlow, S., Achmetli, K., \& Rakoczy, K. (2019.) Does constructing multiple solutions for real-world problems affect self-efficacy? Educational Studies in Mathematics, 100(1), 43-604. https:/ / doi.org/10.1007/s10649-0189847-y

Sergeev, I. N. (2005). Mathematics. Tasks with answers and solutions. Moscow: KDU.

Shestakov, S. A., \& Yurchenko, E. V. (1993). Equations with parameter. Moscow: Slog.

Shivrinskaya, E. V. (2002). Problems with parameters as a means of increasing the motivation of teaching mathematics (PhD). Moscow.

Swetz, F. J., \& Chi, A. Y. (1983). Mathematics entrance examinations in Chinese institutions of higher education. Educational Studies in Mathematics, 14(1), 39-54. https:/ / doi.org/10.1007/BF00704701

The concept of development of mathematics education in the Russian Federation. (2013). Russian newspaper. Retrieved from http:/ / www.rg.ru/2013/12/27/matematika-site-dok.html

Tokareva, V. A., \& Zelenina, N. A. (2016). Laboratory works with the use of the program “Live Mathematics" when teaching students of 7-8 grades to solve problems with a parameter. Scientific-methodical electronic journal "Concept", 9, 91-95. Retrieved from http:/ / e-koncept.ru/2016/46165.htm

Tolpekina, N. V. (2002). Methods of organizing educational research in teaching students to solve equations, inequalities and their systems with parameters (PhD Thesis). Omsk.

Vavilov, V. V., Melnikov, I. I., Olekhnik, S. N., \& Pasichenko, P. I. (2007). Problems in Mathematics. Equations and inequalities. Moscow: Fizmatlit.

Vazhenin, Yu. M. (1997). Tutorial on problem solving with parameters. Ekaterinburg: Ural State University.

Wilkie, K. J. (2016). Rise or Resist: Exploring Senior Secondary Students' Reactions to Challenging Mathematics Tasks Incorporating Multiple Strategies. Eurasia Journal of Mathematics, Science E Technology Education, 12(8), 2061-2083. https:/ / doi.org/10.12973/eurasia.2016.1260a

Yastrebinetsky, G. A. (1986). Problems with parameters. Moscow: Enlightenment.

Zdorovenko, M. Yu., \& Zelenina, N. A. (2018). Replacing a variable in problems with parameters. Scientificmethodical electronic journal "Concept", 7, 82-92. Retrieved from http:/ / e-koncept.ru/2018/186066.htm

Zdorovenko, M. Yu., Zelenina, N. A., \& Krutikhina, M. V. (2016). Using Different Methods for Solving Problems with a Parameter at the Unified State Exam in Mathematics. Scientific-methodical electronic journal "Concept", 8, 139-150. Retrieved from http:/ / e-koncept.ru/2016/16176.htm

Zelenina, N. A., \& Krutikhina, M. V. (2018). Problems of preparing students for final certification in the context of the Unified State Exam results in mathematics in 2017 in the Kirov region. Scientific-methodical electronic journal "Concept", 3, 12-24. Retrieved from http:/ / e-koncept.ru/2018/181011.htm

\section{http://www.ejmste.com}

